\title{
Investigation of the microhardness of the W-Ni- Fe powder alloy used for the restoration of machine parts
}

\author{
Evgeny Ageev ${ }^{1 *}$ and Svetlana Karpeeva ${ }^{2}$ \\ ${ }^{1}$ FGBOU VO South-West state University, 305040, Kursk, Russia \\ ${ }^{2}$ FGBOU VO Orel State University named after I.S. Turgenev, 302026, Orel, Russia
}

\begin{abstract}
The paper presents the results of a study of the microhardness of the WNF-95 sintered electroerosive powder alloy. Powder alloy W-NiFe95 was obtained by electroerosive dispersion of tungsten-containing waste in a kerosene medium. The resulting electroerosive powder alloy $\mathrm{W}-$ $\mathrm{Ni}-\mathrm{Fe}$ 95was pressed in a vacuum chamber and sintered by the method of spark plasma sintering. The aim of this work was to study the microhardness of the WNF-95 sintered powder alloy obtained by the electroerosive dispersion of tungsten-containing waste in a kerosene medium. It has been established that the microhardness of samples sintered by the method of spark plasma sintering from particles of W-Ni-Fe 95alloy dispersed by electric erosion obtained in lighting kerosene is $2185.8 \mathrm{MPa}$ and $2268.0 \mathrm{MPa}$, indicating their suitability for the manufacture of tungsten-nickel-iron alloys.
\end{abstract}

\section{Introduction}

The paper presents the results of a study of the microhardness of the W-Ni-Fe 95 sintered electroerosive powder alloy. Powder alloy W-Ni-Fe 95 was obtained by electroerosive dispersion of tungsten-containing waste in a kerosene medium. The resulting electroerosive powder alloy WNF-95 was pressed in a vacuum chamber and sintered by the method of spark plasma sintering. The aim of this work was to study the microhardness of the W-NiFe 95 sintered powder alloy obtained by the electroerosive dispersion of tungsten-containing waste in a kerosene medium [1-5]. It has been established that the microhardness of samples sintered by the method of spark plasma sintering from particles of W-Ni-Fe 95 alloy dispersed by electric erosion obtained in lighting kerosene is $2185.8 \mathrm{MPa}$ and 2268.0 $\mathrm{MPa}$, indicating their suitability for the manufacture of tungsten-nickel-iron alloys [6-10].

\section{Materials and methods}

\footnotetext{
*Corresponding author: ageev_ev@mail.ru
} 
Waste alloy composition $\mathrm{W}-\mathrm{Ni}-\mathrm{Fe} 95$ was placed in a reactor for electroerosive dispersion, filled with a working liquid - kerosene, electrodes connected to an electroerosive installation were lowered into the reactor (patent for invention of the Russian Federation No. 2449859). Obtaining was carried out according to the scheme presented in figure 1 in four stages:

- Stage 1 - preparation for the process of electroerosive dispersion;

- Stage 2 - the process of electroerosive dispersion;

- Stage 3 - unloading the powder from the reactor and centrifuging it;

- Stage 4 - drying and weighing the powder of the pseudo-alloy of composition W-NiFe.The process of electroerosive dispersion was carried out at a voltage on the electrodes $\mathrm{U}$ $=100 \ldots 110 \mathrm{~V}$, the capacitance of the discharge capacitors $\mathrm{C}=50 \mu \mathrm{F}$, and a pulse repetition rate $v=90 \ldots 160 \mathrm{~Hz}$. Under the influence of short-term electric charges between the electrodes, a breakdown of the working fluid occurs with the formation of fine powder particles [11-12].

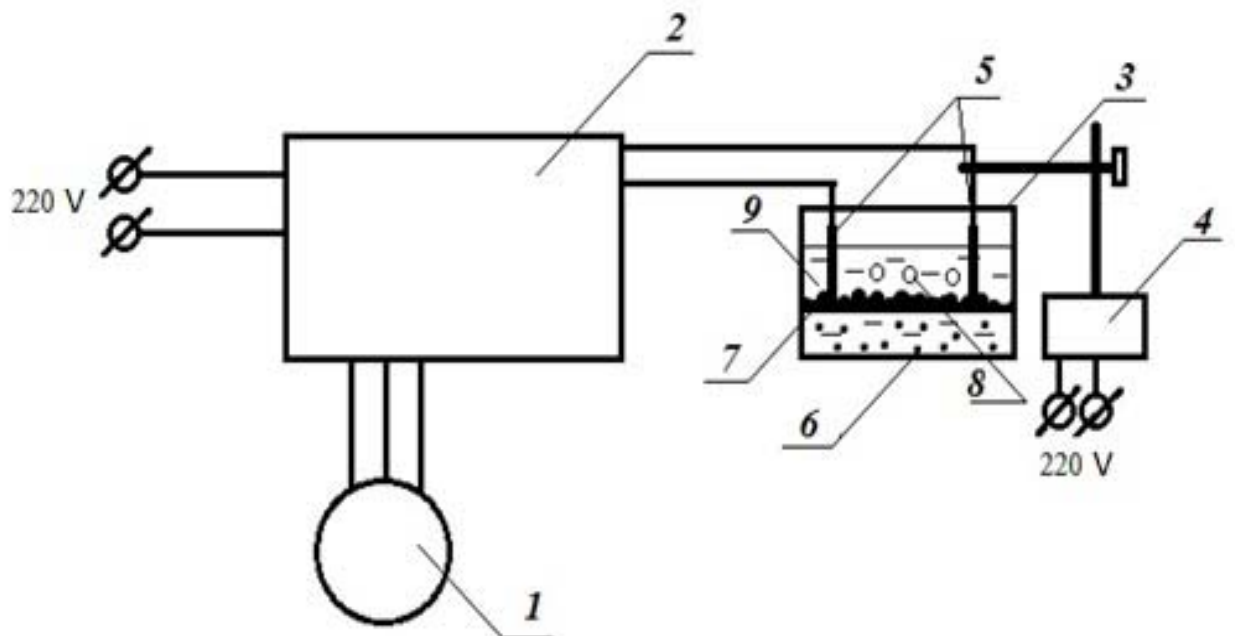

1 - voltage regulator; 2 - pulse generator; 3 - reactor; 4 - shaker; 5 - electrodes; 6 - particles of W$\mathrm{Ni}-\mathrm{Fe} 95$ pseudo-alloy powder; 7 - waste; 8 - gas bubble; 9 - working fluid - kerosene

Fig. 1. Diagram of the process of obtaining dispersed powders from conductive materials by the method of electroerosive dispersion.

The electroerosive powder alloy W-Ni-Fe 95 was sintered by the spark plasma sintering method using the SPS 25-10 system (Thermal Technology, USA).The starting material was placed in a graphite matrix placed under a press in a vacuum chamber. Electrodes, integrated into the mechanical part of the press, supply an electric current to the matrix and create spark discharges between the sintered material particles, ensuring intense interaction. The modes of spark plasma sintering of the electroerosive powder alloy WNF -95 are shown in Fig. 2. 


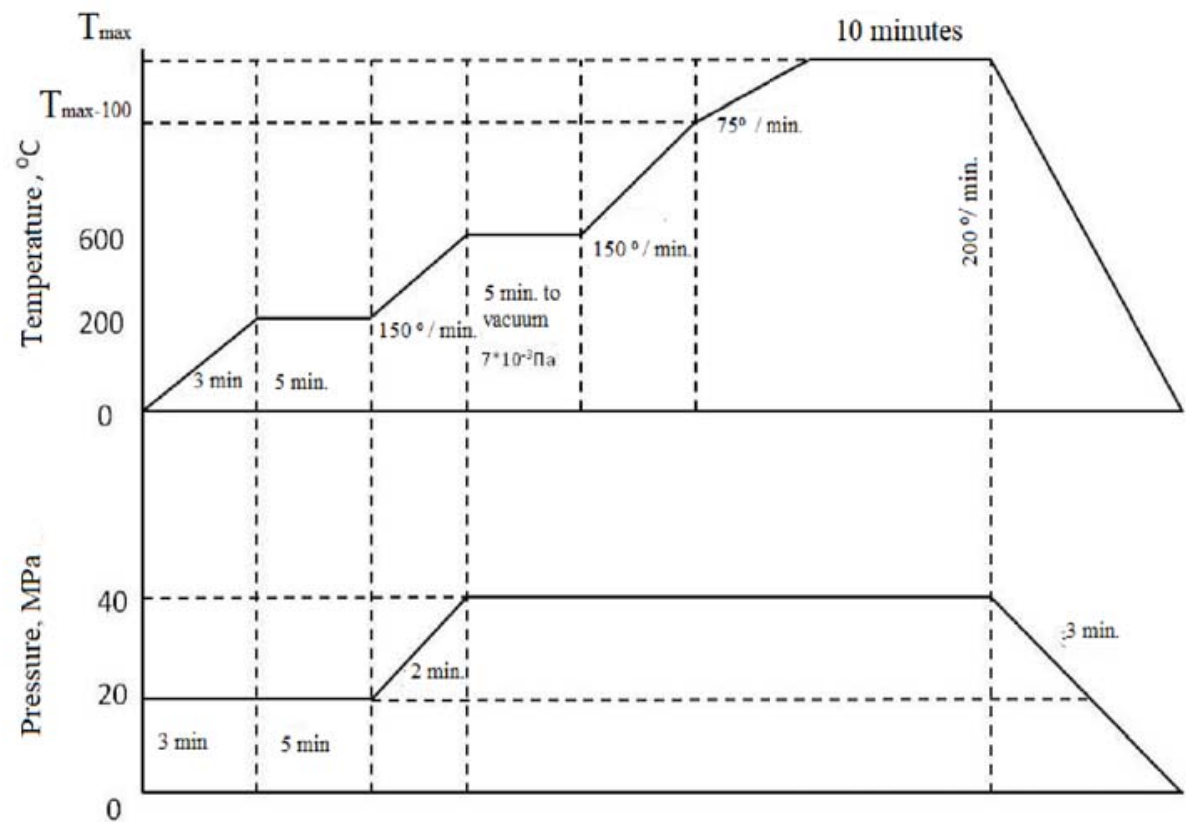

Fig. 2. Sintering modes of electroerosive powder alloy WNF-95 by the method of spark plasma sintering.

The surface of the sample was ground using metallographic paper with coarse (No. 6070) and fine grain (No. 220-240), periodically rotating the sample by $90^{\circ}$. The abrasive particles were washed off with water and subjected to polishing on a wheel with suspensions of metal oxides ( $\mathrm{Fe} 3 \mathrm{O} 4, \mathrm{Cr} 2 \mathrm{O} 3, \mathrm{Al} 2 \mathrm{O} 3)$. After reaching a mirror finish, the surface of the section was washed with water, alcohol, and dried with filter paper (Fig. 3).

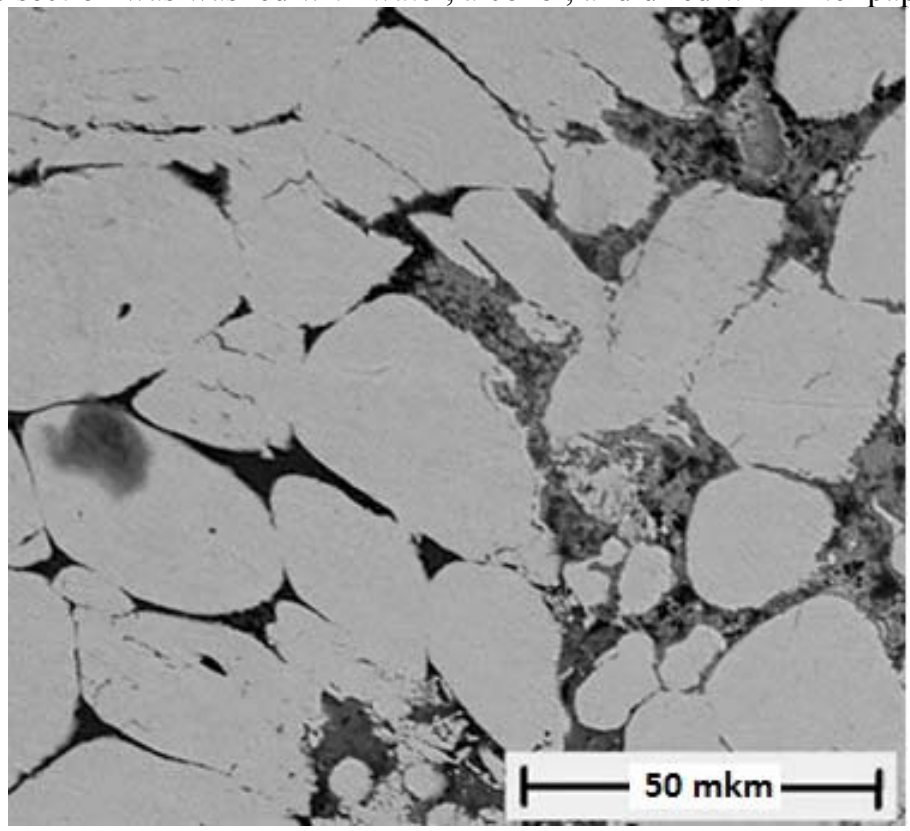

Fig. 3. Microstructure of the cross section. 


\section{Results and Discussion}

Testing the hardness of the samples on the surface and transverse section was carried out using an automatic system for analyzing the microhardness DM-8 by the micro-Vickers method with a load on the indenter of $50 \mathrm{~g}$ for ten prints with a free choice of the injection site in accordance with GOST 9450-76 (Measurement of microhardness by indenting diamond tips ). The indenter loading time was $15 \mathrm{~s}$. The measurement results are shown in Table 1.

It was experimentally established that the microhardness of samples sintered by the method of spark plasma sintering from particles of the WNF 95 alloy dispersed by electric erosion obtained in lighting kerosene is $2185.8 \mathrm{MPa}$ and $2268.0 \mathrm{MPa}$.

Table 1. Vickers microhardness of sintered electroerosive powder alloy W-Ni-Fe 95.

\begin{tabular}{|c|c|c|}
\hline \multirow{2}{*}{ Printnumber } & \multicolumn{2}{|c|}{ Hardness } \\
\cline { 2 - 3 } & Sample 1 & Sample 2 \\
\hline 1 & 211 & 225 \\
\hline 2 & 197 & 190 \\
\hline 3 & 248 & 218 \\
\hline 4 & 197 & 211 \\
\hline 5 & 210 & 198 \\
\hline 6 & 200 & 201 \\
\hline 7 & 212 & 315 \\
\hline 8 & 281 & 214 \\
\hline 9 & 215 & 278 \\
\hline 10 & 214 & 227 \\
\hline Averagevalue (units) $\mathrm{HV}_{0,2}$ & 219 & \\
\hline
\end{tabular}

\section{Conclusion}

Thus, the obtained high microhardness values of the W-Ni-Fe 95 sintered electroerosive powder alloy indicate its suitability for the manufacture of tungsten-nickel-iron alloys.

This work was supported by a grant from the President of the Russian Federation (NSh2564.2020.8).

\section{References}

1. Gu D D, Meiners W, Wissenbach K, Poprawe R., International Materials Reviews, v. 57 133-164. (2012).

2. Song B, Dong S, Zhang B, Materials \& Design, v. 35 120-125. (2012).

3. Song B, Dong S, Coddet P, Surface and Coatings Technology, v. 206 4704-4709. (2012).

4. Wang Z, Guana K, Gaoa M, Journal of Alloys and Compounds, v. 513 518-523. (2012).

5. Karlsson J, Snis A, Engqvist H, Lausmaa J, Journal of Materials Processing Technology, 213 2109-2118. (2013).

6. Safdar A, He H Z, Wei L Y, Snis A, Rapid Prototyping Journal, v. 18 401-408. (2012).

7. Loeber L, Biamino S, Ackelid U, Solid freeform fabrication proceedings, v. 11 547-556. (2011). 
8. Gu D D, Meiners W, Wissenbach K, Poprawe R., International Materials Reviews, v. 57 133-164. (2012).

9. Wang Z, Guana K, Gaoa M., Journal of Alloys and Compounds, v. 513 518-523. (2012).

10. Biamino S, Penna A, AckelidU Intermetallics v. 19 776-781. (2011).

11. Ageev E V, Latypov R A, Russian Journal of Non-Ferrous Metals, 6 577-580. (2014).

12. Latypov R A, Latypova G R, Ageev E V, Altukhov A Y, Ageeva E V, Russian metallurgy (Metally,. 12 1083-1085. (2017). 